\title{
Using Artificial Intelligence to Explore Employment Discrimination and Interview Decision
}

\author{
Li-Bin Chen, Dong-Mei Xu and Shih-Feng Chang* \\ Nanfang College of Sun Yat-Sen University, Guangzhou, 510970, China
}

\begin{abstract}
By comparing college students and enterprise recruiters about the influence of employment discrimination on the interview decision-making bias, we help college students to understand which factors have a greater impact on the interview decision-making, so as to better enhance their competitiveness in the interview process. For enterprise recruiters, through this research, we can understand the current enterprise recruitment which involves employment discrimination behavior for future selection. In addition, we can also judge the ability of talents more objectively.
\end{abstract}

\section{Introduction}

Employment is the foundation of people's livelihood. With the continuous improvement of China's education level, the number of college students in the country is rising. According to The Employment Report of Chinese College Students in 2019 (Blue Book) by Mycos, the proportion of the number of graduates who participate in work in the overall employment situation of 2018 undergraduate graduates is $73.6 \% ; 1.8 \%$ chose to start their own business; $16.8 \%$ and $3.3 \%$ chose to take part in the postgraduate entrance examination, including those who are studying for postgraduate entrance examination and those who are preparing for postgraduate entrance examination. Under the situation of great employment pressure, delaying employment has gradually become a trend, but employment is still the first choice for most college students after graduation.

It is said that "heroes don't ask where they come from", but more and more college students feel that they are not on the same starting line with other job seekers in the interview process, and this phenomenon also occurs in many recruitment units. In the past, knowledge and skills, work experience, educational background and other conditions are the stepping stones for college students to get an offer. However, some research has found that in recent years, appearance is the performance image. In addition, gender has become a competitive factor in the job market.

Under the above background, we attempt to investigate the employment discrimination in college students' job hunting and enterprise recruitment units, to verify the degree of employment discrimination in the process of undergraduate graduates' job hunting, to explore the underlying reasons, and to provide operational suggestions for the relevant management agencies, in order to improve the discrimination behavior of undergraduate graduates in the job market.

\section{Literature Review}

"Discrimination" is one-sided view of a person's defect or origin with an unequal perspective (most of which are subjective factors), so that he or she can get different degrees of loss in life or job hunting, which is often derogatory. The definition of "employment discrimination" in this research is that in China's labor market, the decision-making results made by interviewers due to personal subjective factors are not fair to job seekers. The objective evaluation of work ability involves the evaluation that has nothing to do with personal work productivity. This kind of behavior that hinders workers from obtaining equal employment opportunities is "employment discrimination".

In domestic research and design of employment gender discrimination, there are scenario simulation analysis and virtual matching resume (Ge Yu-Hao, Deng Jia-Meng and Zhang Shuai, 2018; Zhang Yan-Mei, 2017) [1] [8]. Wen-Bin Zhang(2016) said that the main problems faced by college students' employment in China are the large population of college students, professional deviation and psychological deviation in employment, so they can't really find out their own preferences and ideas [5]. In the recruitment process, the interviewers will be influenced by social and cultural traditions, and the decision-making management posts are more male and the internal service posts are more female (Luo Juan, 2018) [4]. Yong-Ping He, Yan Xiong and Ping Guo (2011) proposed that only when the ability of male college students is equal to that of female college students, and the employment rate of male college students is higher than that of female college students, can we prove that there is gender discrimination in the process of employment, and only when they are not treated by work can there be 
gender discrimination [7]. Besides, Xiong Yi-Qing and Lee He-Wei (2010) found that graduates from key colleges in China are more likely to be employed and less likely to suffer from education background discrimination [6]. According to the survey, $97.2 \%$ of the recruiters admit that the "first impression" of the candidates may or will definitely affect their recruitment decision-making ( $\mathrm{Lu}$ Mei-Yu, 2018) [3]. In addition, job seekers with high appearance attractiveness are more likely to be employed than those with low appearance attractiveness (Lee Ying$\mathrm{Wu}, \mathrm{Han}$ Xiao and Yu Zhou, 2014) [2].

In view of this, through literature review above, we found that the discrimination faced by domestic college students in the process of employment mainly includes gender, education background and appearance.

\section{Research Method}

We collected the data about employment discrimination in gender, education background and appearance at home and abroad, explored the influence of gender, education background and appearance on interview decisionmaking in the process of employment, and constructed the theoretical model of this research.

The scale of this research refers to the previous questionnaire scale of employment discrimination related research topics, some of the topics are self-made, according to different survey objects, for students and enterprise recruiters, two scales are made, each scale has 20 questions, using Likert five point scoring method, the subjects choose the best option to express their attitude according to the topic, from "very disagree" to "very disagree". The score of "very agree" is 1-5.

Moreover, we also use AI analysis tool Python and SPSS statistical analysis to verify the theoretical hypothesis by descriptive analysis, reliability and validity test, factor analysis and correlation analysis.

\section{Research Results}

In the questionnaire data analysis for college students, the respondents are college students of different levels. The valid number of questionnaires is 157. Among them, $49.68 \%$ of the sample think that appearance has the greatest impact on the interview decision-making, followed by education background, and finally gender. The results show that the three factors of employment discrimination (gender, education background and appearance) do have different degrees of influence on interview decision-making. Comparing the mean value of "big eyed job seekers are attractive to interviewers (3.00)" with "slim and curvilinear job seekers are attractive to interviewers (3.71)", it shows that slim and curvilinear job seekers are more attractive to interviewers. The mean value of the item "are there differences in working abilities between women and men?" is 3.01, which has the lowest score in the same dimension. It shows that the sample does not recognize the difference of working ability between men and women. The average score of the item "employers only recruit 985 / 211 college students, (there is) academic discrimination" (3.92) was the highest in the same dimension and all descriptive analysis measurement items, indicating that the sample recognized this behavior as academic discrimination in job hunting.

The enlightenment from this is that college students perceive that college students with high grade, slim and moving figure will be the factors of successful interview, and they think that there is no difference between men and women in work ability, so they should be treated equally.

The reliability of the questionnaire is 0.860 , greater than 0.8 , which indicates that the reliability of the questionnaire is high and can be used for analysis. In addition, the KMO value of the sample data is 0.872 , greater than 0.8, and Bartlett Spherical Test is significant $(0.000)$, which indicates that the validity of the research data is very good and suitable for factor analysis.

In this research, the maximum variance rotation method is used to observe the influence of each factor on the research item, so as to find out the corresponding relationship between the factor and the research item. The greater the absolute value of the load coefficient, the greater the role of the factor explanation (positive and negative). The value of the item "985/211 college students' strong working ability is the reason for their preference" is less than 0.4 , indicating that the relationship between the factor and the research item is very weak, this item should be deleted and analyzed again. Therefore, we remove the item "985 / 211 college students' preference reasons" and conduct factor analysis again to get the table of variance explanation rate. Besides, we can see that three factors are extracted from the sample data, and the eigenvalue values are greater than 1 , and the cumulative variance explanation rate of the three factors after rotation is $65.905 \%$, which belongs to the acceptable range.

In this research, the relationship between employment discrimination and interview decision-making is discussed by taking the three factors extracted: appearance, gender and education background as independent variables and taking interview decision-making as dependent variables.

From the results of correlation analysis in Table 1, we can see that the correlation coefficients between the mean value of interview decision-making and the mean value of appearance factor, gender factor and education background factor are 0.0676, 0.0734 and 0.0705, respectively, and all of them are significant. There is a positive correlation between the average of gender factor and the average of college grade factor. 
Table1. Pearson correlation analysis results

\begin{tabular}{|c|c|c|c|c|}
\hline item & $\begin{array}{c}\text { mean value of } \\
\text { interview decision }\end{array}$ & $\begin{array}{c}\text { appearance will } \\
\text { affect the result of } \\
\text { employment }\end{array}$ & $\begin{array}{c}\text { gender will } \\
\text { affect the result } \\
\text { of employment }\end{array}$ & $\begin{array}{c}\text { education background } \\
\text { will affect the result of } \\
\text { employment }\end{array}$ \\
\hline $\begin{array}{c}\text { mean value of } \\
\text { appearance factor }\end{array}$ & $0.0676^{*}$ & $0.0791^{*}$ & $0.0445^{* *}$ & $0.0288^{* *}$ \\
\hline $\begin{array}{c}\text { mean value of sex } \\
\text { factor }\end{array}$ & $0.0734^{*}$ & $0.0499^{* *}$ & $0.0764^{*}$ & $0.0363^{* *}$ \\
\hline $\begin{array}{c}\text { mean value of } \\
\text { education } \\
\text { background factor }\end{array}$ & $0.0705^{*}$ & $0.0500^{*}$ & $0.0518^{*}$ & $0.0548^{*}$ \\
\hline
\end{tabular}

\section{Conclusions and Suggestions}

Getting equal employment opportunities is not only the hope of college students, but also the voice of all labor talents. No matter at home or abroad, how to eliminate employment discrimination, ensure the implementation of policies, and improve the social status and labor value of workers has always been a major problem to be solved in the research of employment discrimination.

At present, China's employment development is unbalanced and inadequate. Therefore, to stabilize the employment situation is social stability and the overall situation of the country is stable. China's college graduates are one of the national key employment groups. Moreover, to promote the employment development of college graduates is inseparable from the cooperation between the government, schools, employers and students.

With the development of social economy, more and more enterprises are increasing their demand for diversified talents in order to meet the development trend and improve their competitiveness. In view of this, non 985 / 211 colleges should reform the direction and mode of education, pay attention to the cultivation of highly competitive and diversified talents suitable for social development, and ease the employers' demand for talents of non 985 / 211 colleges.

In order to improve the overall employment rate and employment quality of college students, 211 college students form prejudice 211 colleges should explore their own characteristics, most of which are local colleges and universities. Besides, non 985 / 211 colleges should optimize the subject structure and professional curriculum, pay attention to the cultivation of college students' innovation ability and comprehensive quality, encourage independent entrepreneurship, and cultivate talents to meet the needs of the local market, so as to achieve higher quality and fuller employment based on fairness.
However, there is no way to really eliminate employment discrimination in a short time, but college students are one of the key employment groups and the main force of the future labor market. Therefore, in addition to cultivating their own professional ability, college students should tap their own strengths and interests with the help of the school, and cultivate their own professional quality and employ ability as soon as possible.

\section{References}

1. Ge Yu-Hao, Deng Jia-Meng, Zhang Shuai (2018) Is there sexism among college students? Methods based on virtual matching resume. Economics, 17 (4): 1289-1304.

2. Lee Ying-Wu, Han Xiao, Yu Zhou (2014) Is beauty good? Attractiveness and personnel selection decision. China Human Resources Development, 23: 23-29.

3. Lu Mei-Yu (2018) The influence of job seeker image on interviewer's decision-making: The intermediary effect of perceptual perception and rational perception. Master's Thesis of Institute of Business Administration of East China Normal University.

4. Luo Juan (2018) Analysis of gender discrimination in the recruitment of college graduates by enterprises. Theory and Research, 12: 31.

5. Wen-Bin Zhang (2016) On the problem analysis and countermeasures of employment discrimination of college students in China. Business, 4: 18.

6. Xiong Yi-Qing, Lee He-Wei (2010) On discrimination of school grades and academic qualifications in the employment of university graduates. Journal of Yunnan Radio and TV University, 12 (4): 31-34. 
7. Yong-Ping He, Yan Xiong, Ping Guo (2011) Causes and countermeasures of gender discrimination in college students' employment. Chinese Youth Studies, 3: $98-100+34$.

8. Zhang Yan-Mei (2017) A study on gender discrimination in employment of female college students based on the analysis of 380 college students. Master's Thesis of China Youth Political College. 